\title{
Study on spatial-temporal change of soil organic carbon and impact factors in Gudao Forestry Farm of Dongying
}

\author{
Shengnan Zhang ${ }^{1}$, Zhanhong Liu ${ }^{1}$, Luo Fang ${ }^{1}$, Baolin $\mathrm{Wu}^{1}$, Yurui $\mathrm{Li}^{1}$, Yan $\mathrm{Ning}^{1}$ \\ ${ }^{1}$ School of Water Conservancy and Environment, University of Jinan, 250022 Jinan, China
}

\begin{abstract}
Soil organic carbon (SOC) is one of the important properties to evaluate soil quality, which can indirectly reflect the effect of afforestation on saline-alkali land. In this study, 4 different forest types in Gudao Forestry Centre were selected as experimental plots, and bare land was set as blank group. Spatial differentiation and impact factors of SOC between different forest types were studied by field investigation and laboratory experiment. The results show that (1) SOC content in the study area is lower than $1 \%$. SOC content in forest land is higher than that in bare land. In the upper soil layer, the SOC content of Robinia Pseudoacacia forest is lower, and mixed forest is higher. SOC content of bare land is higher than that of forest land in the lower layer. (2) SOC has a significant positive correlation with available nutrients $(\mathrm{P}<0.05)$, and has a weak correlation with $\mathrm{pH}$ and water content. There are different correlations with conductivity and bulk density in different soil layers, and they all showed a negative correlation at the upper layer, and a significant positive correlation at the lower layer $(\mathrm{P}<0.05)$.
\end{abstract}

\section{Introduction}

The Yellow River Delta is abundant in land resources, but environment is fragile, with poor soil and low biodiversity ${ }^{[1]}$. Through long time experiment, it is found that the cultivation of fast-growing tree species and native species can improve the soil quality of the Yellow River Delta very well ${ }^{[2]}$. Therefore, this paper try to explore the spatial and temporal characteristics of SOC and its influencing factors, through the laboratory analysis of soil physical and chemical properties under different forest types and different periods, in order to provide a basic theoretical basis for the construction of forest land in the Yellow River Delta and the protection and restoration of fragile ecosystems.

\section{Study area and methods}

\subsection{Study area}

Gudao Forestry Farm is located in Hekou District of Dongying, Shandong Province ( $37^{\circ} 53^{\prime} 22^{\prime \prime} \sim 37^{\circ} 56^{\prime}$ $17^{\prime \prime} \mathrm{N}, 118^{\circ} 45^{\prime} 38^{\prime \prime} \sim 118^{\circ} 51^{\prime} 40^{\prime \prime}$ E). It spans Gudao town and Xianhe town, with a total area of about $2689 \mathrm{hm}^{2}$. The forest farm is about $20 \mathrm{~km}$ away from the Bohai Bay and near the estuary of the Yellow River. The area is located in the middle latitude, facing the sea and backing to the land. This area is temperate monsoon climate with four distinct seasons, hot and rainy at the same time. Most of the vegetation in the forest farm is planted artificially in the later stage, among which locust (Robinia pseudoacacia) is the main tree type, while a small amount of elm (Ulmus pumila), paper mulberry (Broussonetia papyrifera) are cultivated, and most of them are pure artificial forest. Tamarisx (Tamarix chinensis) is the main shrub species and the main herbal plants are reed (Phragmites australis), rape (Brassica napus), mustard (Hemistepta lyrata) and so on.

\subsection{Field sampling and investigation}

The data used in this paper were obtained through field sampling and laboratory testing. The sampling period was one year, and the field sampling was conducted 4 times (2018.8.10, 2018.10.24, 2018.12.22, 2019.4.25). Locust forest, mixed forest, white wax forest and tamarisx forest were selected as the experimental groups, one bare land was set as the control group. The location of the sample points showed in Fig. 1. The forest and soil characteristics such as diameter at breast height (DBH), stand density (SD), canopy density (CD), tree height, soil organic carbon (SOC), electrical conductivity (EC), $\mathrm{pH}$ value, soil bulk density (BD), and available nutrients were measured (Table. 1).

At each sampling point, the DBH of 200 trees was measured to find the standard $\operatorname{trees}^{[3]}$. Soil profiles with a depth of $50 \mathrm{~cm}$ were set near the stanndard trees. The profiles were divided into upper and lower layers (upper layer: $0 \sim 25 \mathrm{~cm}$, lower layer: $25 \sim 50 \mathrm{~cm}$ ). Three soil samples were taken from each layer with a ring knife and put it in the aluminium box weighed in advance. The total weight was instantly weighed with a electric balance, then sealed it up immediately and brought them back to the laboratory. $1 \mathrm{~kg}$ soil from upper layers and lower layers respectively was picked up into a bag with a small shovel, labeled them

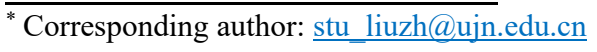


and brought them to the laboratory.

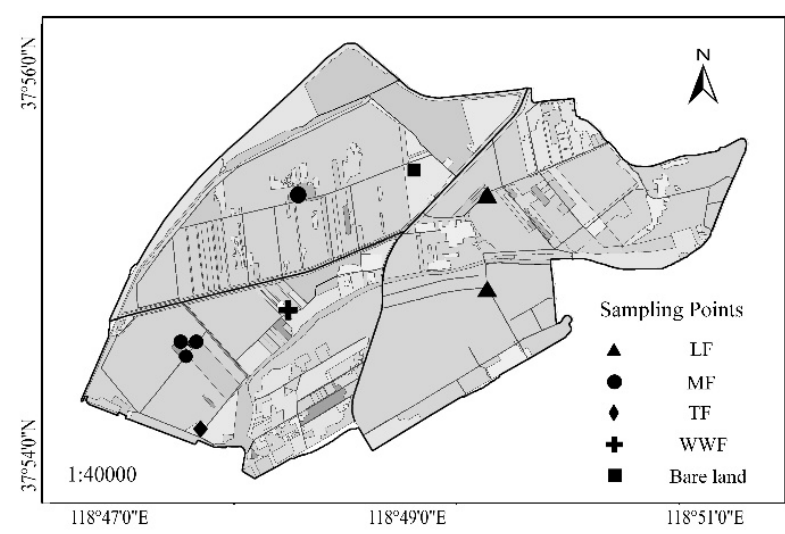

Fig.1. The distribution of sampling points

\subsection{Laboratory experiment methods}

Soil samples which were taken with aluminium boxes and ring knifes in the field were baked in an oven at $105^{\circ} \mathrm{C}$ for about 8 hours to reach constant weight, and then measured the soil moisture content and soil bulk density ${ }^{[4]}$. The other soil was placed in a ventilated place to air-dry naturally, then grind the soil samples and pass through $2 \mathrm{~mm}$ sieves for reserve. Soil conductivity was determined by the electrode method, $\mathrm{pH}$ value by potentiometry method, available nutrients by spectrophotometry method and soil organic carbon by Walkey- Black method ${ }^{[5]}$.

Three $10 \mathrm{~m} \times 10 \mathrm{~m}$ quadrangles were set in each point to measure SD, coverage and other characteristics. Forest age data were obtained from the recorded data of forest farm over the years. Data analysis was conducted by excel software.

\section{Result and Analysis}

\subsection{Spatial distribution of SOC}

SOC in this study area is at a low level as a whole, and its content is generally less than $1 \%$.

Table 1. Vegetation information of the study area

\begin{tabular}{|c|c|c|c|c|c|c|c|}
\hline Forest types & Abbreviation & Stands & $\mathrm{DBH} / \mathrm{cm}$ & Height $/ \mathrm{m}$ & $\mathrm{SD} /\left(\mathrm{n} \cdot \mathrm{hm}^{-2}\right)$ & Coverage & Age/a \\
\hline Locust forest & LF & Robinia pseudoacacia & 13.22 & 10.25 & 2400 & 0.87 & 30 \\
\hline Mixed forest & MF & $\begin{array}{l}\text { Ulmus pumila } \\
\text { Broussonetia papyrifera }\end{array}$ & 11.14 & 8.44 & 2133 & 0.72 & 7 \\
\hline White wax forest & WWF & Fraxinus chinensis & 10.41 & 4.56 & 3600 & 0.3 & 6 \\
\hline Tamarisx forest & $\mathrm{TF}$ & Tamarix chinensis & 3.93 & 2.75 & 10000 & 0.67 & 4 \\
\hline
\end{tabular}

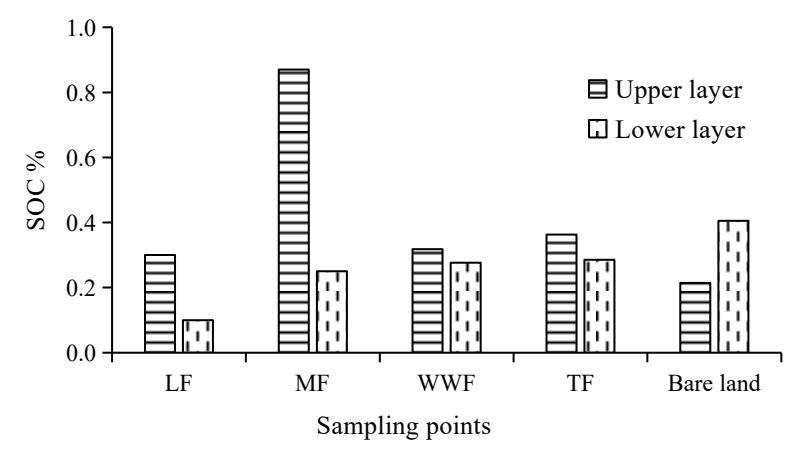

Fig. 2. Soil organic carbon of different forest types

In the upper layer the SOC content is $0.21 \sim 0.97 \%$, among which the SOC content in locust forest is less than that in other forest types. The reason is that the effective roots of locust mainly distribute in the soil layer of $0 \sim 60 \mathrm{~cm}$, the nutrient absorption of roots is larger, and the soil is loose and ventilated well, which is conducive to the decomposition of SOC, so its content is not high. Comparatively speaking, the content of SOC in mixed forest is high, which may be explained as the strong accumulation and fine soil texture. Mixed forest has a red clay layer $25 \sim 30 \mathrm{~cm}$ away from the surface, where the texture is compact, and the upper SOC is not easy to leach to the lower layer, resulting in the accumulation of SOC in the upper layer.

The content of SOC in the lower layer ranges from $0.07 \%$ to $0.41 \%$. SOC content in bare land is significantly higher than that in other 4 forest types, which is closely related to the no vegetation interception and strong leaching.

Comparing the SOC in the upper and lower layers of the same forest type, it is found that the content of SOC

in the upper layer is higher than that in the lower except bare land. The reason may be related to the difference of litter amount and soil physical and chemical properties in the surface layer. The bare land lacks vegetation coverage and external supplement of SOC, and under the effect of long-term precipitation leaching, rare $\mathrm{SOC}$ in the upper layer migrates to the lower.

\subsection{Temporal change of SOC}

Taking August as the growing season and December as the non-growing season, it can be seen from Fig. 3 and Fig. 4 that the content of SOC in the growing season was generally lower than that in the non-growing season. In the growing season, the humification process and is microbial activity are relatively strong duo to high temperature and humidity, on the other hand, the plant growth needs more organic matter. After the growing season, with the temperature and soil microbial activity 
decreasing, the amount of SOC collected by plant roots from the soil also decreases greatly, so the amount of SOC absorption decreases less than that produced by decomposition of litter humus. As a result, SOC is accumulated in non-growing season.

\subsection{Analysis of SOC influencing factor}

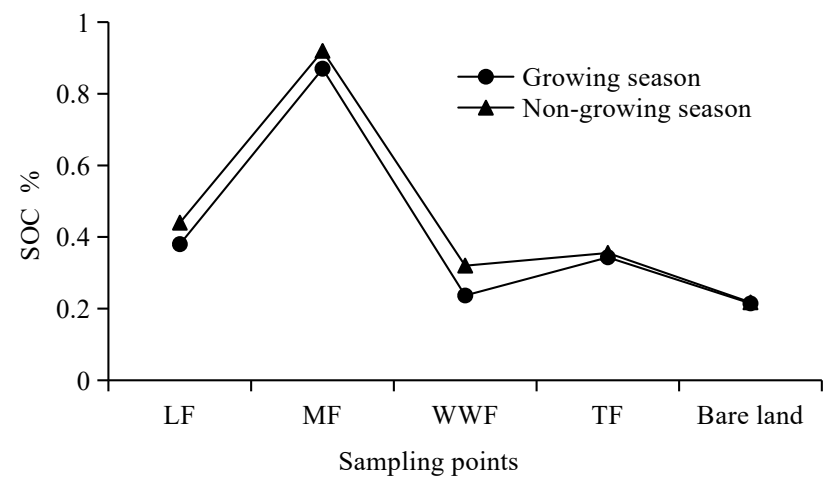

Fig. 3. Soil organic carbon in the growing season
Correlation analysis reveals that all soil characteristics in the lower layers have significant correlation with soil SOC under all the different forest types (Table. 2). Soil $\mathrm{pH}$ in the lower layer shows significant negative correlation with SOC in the lower layers $(R=-0.916$, $\mathrm{P}<0.01)$.

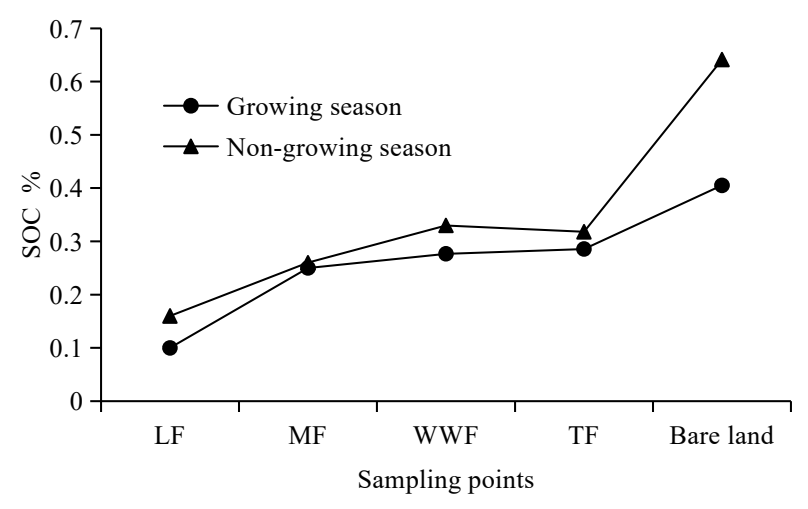

Fig. 4. Soil organic carbon in the non-growing season

Table 2. Correlations between SOC and different factors

\begin{tabular}{lcccc}
\hline \multirow{2}{*}{$\begin{array}{c}\text { Correlation } \\
\text { factors }\end{array}$} & Upper layers & \multicolumn{2}{c}{ Lower layers } \\
\cline { 2 - 5 } & Linear regression equation & $\mathrm{R}$ & Linear regression equation & $\mathrm{R}$ \\
\hline $\mathrm{BD}$ & $\mathrm{y}=-0.235 \mathrm{x}+1.517$ & $-0.766^{*}$ & $\mathrm{y}=1.260 \mathrm{x}+1.113$ & $0.861^{* *}$ \\
$\mathrm{pH}$ & $\mathrm{y}=-0.676 \mathrm{x}+6.388$ & -0.154 & $\mathrm{y}=-0.509 \mathrm{x}+4.636$ & $-0.916^{* *}$ \\
$\mathrm{EC}$ & $\mathrm{y}=-0.169 \mathrm{x}+0.754$ & -0.557 & $\mathrm{y}=0.092 \mathrm{x}+0.171$ & $0.720^{*}$ \\
Water content & $\mathrm{y}=0.011 \mathrm{x}+0.396$ & 0.112 & $\mathrm{y}=0.023 \mathrm{x}-0.207$ & $0.797^{*}$ \\
Ammonium N & $\mathrm{y}=0.028 \mathrm{x}+0.205$ & $0.794^{*}$ & $\mathrm{y}=0.022 \mathrm{x}+0.144$ & $0.729^{*}$ \\
Available P & $\mathrm{y}=0.055 \mathrm{x}-0.826$ & $0.797^{*}$ & $\mathrm{y}=0.014 \mathrm{x}+0.051$ & $0.710^{*}$ \\
Available K & $\mathrm{y}=0.019 \mathrm{x}+0.045$ & $0.940^{* *}$ & $\mathrm{y}=0.007 \mathrm{x}+0.214$ & $0.701^{*}$ \\
\hline
\end{tabular}

$* \mathrm{P}<0.05, * * \mathrm{P}<0.01$

The electrical conductivity and SOC shows the positive correlation significant in the lower layers $(\mathrm{R}=0.720, \mathrm{P}<0.05)(\mathrm{R}=0.861, \mathrm{P}<0.05)$, and no significant correlation in the upper layers $(\mathrm{R}=-0.557, \mathrm{P}>0.1)$. The correlation between $\mathrm{BD}$ and SOC is significant, but showing the converse trend in upper and lower layers. The upper layer shows positive correlation $(\mathrm{R}=0.861, \mathrm{P}<0.01)$, while the lower layer shows negative correlation $(\mathrm{R}=-$ $0.766, \mathrm{P}<0.05)$. The reason might be strong leaching effects under the high bulk density, which lead to the soil accumulation difficultly in the upper layers. There is a positive correlation between water content and SOC in the lower layers $(\mathrm{R}=0.797, \mathrm{P}<0.05)$. Soil available nutrients (ammonium nitrogen, available phosphorus, available potassium) and SOC shows significant positive correlation in all layers $(\mathrm{P}<0.05)$, which may be that available nutrients promoted plant growth and further accumulated a large number of SOC.

\section{Conclusion}

Gudao Forest Farm in Dongying was taken as the research area, and 4 forest types were selected as the research sample plots. The temporal and spatial differentiation characteristics of SOC and the impact factors of SOC were explored through investigation and experiments. The results show that:

(1) The content of SOC in the study area is general lower than $1 \%$. SOC content in forest land is higher than that in bare land. The content of SOC in the upper layers range from $0.21 \%$ to $0.97 \%$. The content of SOC under locust forest is lower, mainly affected by its root distribution, while that of mixed forest is higher, which is related to the root interception and storage of red clay layer. In the lower layers, the content ranges from $0.07 \%$ to $0.41 \%$. The content of bare soil is significantly higher than that in woodland.

(2) The content of SOC in lower layers has significant positive correlation with $\mathrm{EC}, \mathrm{BD}$, water content and available nutrients, but all the impact factors except available nutrients in upper layers has no significant correlation with SOC 


\section{Acknowledge}

This paper is sponsored by Dongying Forestry Bureau (W18145) and Ph.D. Programs Foundation of University of Jinan (XBS1816, XBS1818).

\section{References}

1. G. L. Zhang, J. H. Bai. Comprehensive assessment of soil quality of wetlands in the Yellow River Delta. Wetland Science. 13, 744-750 (2015)

2. L. Y. Zhang. Analysis of major improving measures on saline-alkali soil of Yellow River Delta. Jounal of Anhui Agri Sci. 35, 5266-5309 (2007)

3. M. H. Guo. Study on the estimation of storage volume by mean $\mathrm{DBH}$ and number of stands. East China Forest Management. 18, 6-9 (2014)

4. S. Ghosh, B. C. Scharenbroch, L. Soil organic carbon distribution in roadside soils of Singapore. Chemosphere, 165, 163-172 (2016)

5. A. Walkley, I. A. Black. An examination of Degtjareff method for determining soil organic matter and a proposed modification of the chromic acid titration method. Soil Sci. 37, 29-37 (1934). 